Revista de Investigación en Psicología. Vol. 2, Nº 1. pp. 31 - 72

\title{
EL RORSCHACH EN FAMILIAS UNIPARENTALES *
}

\author{
Dora Frisancho Vera \\ Anal Fairlie Altez \\ Elena Zurita Macalupú
}

Se analiza la personalidad de los niños que pertenecen a familias uniparentales haciendo uso del Psicodiagnóstico de Rorschach -variante Exner 1978-, se comparan las variables del test en dos grupos de niños, uno de familias completas y otro de uniparentales. Las diferencias calculadas con significación estadística proponen un cuadro Rorschach en condiciones premórbidas que puede derivar de la crianza dentro de familias incompletas y que podría socavar de modo incipiente la estabilidad psíquica. Este resultado comparte con otros autores la probable presencia de un componente depresivo de fondo.

Palabras clave: Niños, familias uniparentales, depresión.

It is analyzed the personality of the children that belong to families with only one parent. Making use of the Rorschach Psychodiagnostic -Exner 1978 version-, are compared the variables of the test in two groups of children, one of complete families and other of only one parent. The differences calculated with statistic meaning propose a Rorschach frame in pre-morbid conditions that it can derive from the breeding within incomplete families and that would undermine in incipient manner the psychic stability. This result shares with other authors the probable presence of a depressive inner component.

Key words: Children, Families, one parent family, depress ion. 
Es conocido que en las últimas décadas de este siglo se viene intensificando el estudio de la familia como sistema particular de interacción. Uno de los problemas que nos convoca particularmente a reflexión es el de las familias incompletas por ausencia de uno de los padres y su concomitante de familias que se constituyen sobre la base de madres solteras. La estructura de la familia nuclear integrada por ambos padres e hijos nos parece la constante normal de nuestras sociedades y es por eso que preocupa el incremento masivo de familias que no llegan a completarse. Los niños que crecen en estas condiciones deben presentar particularidades de comportamiento dignas de ser analizadas. Estas particularidades deben plasmarse en la personalidad infantil, y es aquí donde los tests psicológicos pueden ayudar a definirlas.

Coincidentemente, ha sido preocupación nuestra permanente la estandarización del test de personalidad del Psicodiagnóstico de Rorschach con el fin de contribuir a establecer pautas de interpretación que correspondan a las características de nuestra gente. Desde años anteriores hemos baremizado el Rorschach para muestras de la capital de niños de uno y otro sexo entre edades de seis a diez años y contando con estos resultados es que nos sentimos con las condiciones suficientes para registrar los perfiles y los rasgos de la personalidad infantil individual y de grupos en nuestro medio. Es así que nos fijamos el propósito de estudiar a través del Rorschach lo que acontecía con los niños de familias uniparentales.

Al comparar los protocolos de estos niños con los de familias completas resultan diferencias significativas en algunos indicadores del test que se transparentan en su simpleza y objetividad. Pero cuando hay que saltar de allí a las interpretaciones no podemos obviar totalmente las dificultades y tenemos que admitir que nos hallamos en terreno movedizo. Nos hemos esforzado por armonizar los distintos criterios que la literatura de la especialidad ofrece y en la discusión de los resultados presentamos algunas observaciones que deben recordarse para ser lo menos unilaterales. Es un hecho que el esclarecimiento de lo que acontece con la personalidad de nuestros niños a través del test del Rorschach apenas comienza y no debe dejar de ser objeto de la indagación psicológica, particularmente cuando se 
trata de cuestiones sociales palpitantes como los que acarrea la uniparentalidad.

\section{FAMILIAS UNIPARENTALES}

Desde fuentes distintas se admite que en nuestras sociedades monogámicas se extiende cada vez más el fenómeno de las familias uniparentales. En 1994 nosotros hemos tratado el tema en un trabajo de investigación titulado "El trastorno mental por ausencia paterna" donde comparamos familias completas y uniparentales buscando los efectos psicológicos que afectan a los hijos por la falta del padre. Revisamos allí a grandes rasgos lo que había al respecto en la literatura a nuestro alcance y percibimos luego que teníamos mucho que indagar aparte de lo que planteábamos inicialmente.

Se verifica desde los cincuenta cambios en el equilibrio de poder familiar y su correlato en la conducción del hogar y de los hijos que está pasando de manos del esposo-padre a las de la esposa-madre. En diversas partes de nuestro mundo aumenta el número de hogares donde se diluye el papel de la autoridad paterna tradicional y los hijos sólo cuentan con el ejemplo de la madre. En términos de Parsons, la conducción de la familia viene perdiendo su función "instrumental" y en su lugar prepondera la función "expresiva", yen el enfoque de Zuk están primando los valores de "continuidad" representados en el comportamiento materno por sobre los de "discontinuidad" liderados por la figura paterna que cada vez tiene menos vigencia en la vida familiar. Estos autores y otros más derivan de ese hecho cultural el alejamiento por parte de los hijos de los valores que representa el padre vinculados a la ley, el orden, la razón y la eficiencia en el manejo de los asuntos prácticos de la vida en sociedad. En su lugar adhieren a los valores maternos de continuidad de las tradiciones del humanitarismo. La imagen del padre es vinculada a la sociedad legal y los jóvenes, en consecuencia, manifiestan una "alarmante" falta de simpatía por el ordenamiento social y cultivan distintas formas de rebeldía y de comportamiento antisocial.

Como consecuencia de las guerras y el alistamiento militar, y particularmente luego de la Segunda Gran Guerra Mundial, se observaba desde antes de mediados de siglo el fenómeno uniparental por ausencia del 
padre y, por ejemplo, Porot (1962) resumía en tres sus consecuencias: 1) dificultad material debido a la ausencia del responsable del provisionamiento de los recursos de vida, 2) dificultades en el curso de los procesos evolutivos de los hijos, como el de identificación y 3) inadaptación social que suele extremar en forma de perversiones instintivas condicionadas. Porot sentenciaba: "Lo más corriente es que acarree una mala adaptación social que se manifestará por la incapacidad de fundar un hogar aceptable y, sobre todo, de mantenerlo, o por toda la gama de la delincuencia juvenil, más tarde adulta" (p. 160).

Un resumen de lo observado por autores norteamericanos como Goodyear, Muller y Cooper y Verna y Finlay aparece en la revista Psykhe de Santiago de Chile, donde los síntomas de los hijos que han perdido al padre se agrupan en tres niveles de edad, a saber:

Preescolares: Agresividad, ansiedad, tendencia al acting-out, síntomas depresivos, conductas regresivas, transtornos del sueño y disminución de la participación en actividades sociales, retraimiento y aislamiento.

Escolares: Síntomas afectivos: temores-miedo en relación a la posibilidad del reemplazo parental, rabia hacia ambos padres desplazada hacia los hermanos, profesores y pares, conductas agresivas y antisociales (especialmente ante los varones), retraimiento social y bajas en el rendimiento académico; y Adolescentes: La rabia que acompaña a la persona es dirigida especialmente hacia el padre que deja el hogar, y se registra en este grupo la mayor incidencia de embarazos.

A ello se agrega una sintomatología posterior que queda como rastro del trauma de la separación paterna ya en la vida adulta de los hijos; en niveles socioeconómicos bajos el índice de separaciones es igualmente alto y es menor el grado educacional que alcanzan.

Los autores del artículo de la revista, Reinoso y Serrat, llaman la atención sobre la falta de "estudios empíricos nacionales" al respecto. Por su parte McConnell (1978) ofrece su propio resumen:

"Estudios subsecuentes indicaron que los niños criados sin padre eran menos agresivos, más dependientes, y tenían más patrones femeninos de intereses y de juego que los chicos criados en familias normales. Aunque estos patrones afeminados de conducta sí tendían a disminuir cuando ingresaban los 
chicos a la escuela y empezaban a responder a presiones sociales externas al círculo familiar, algunos de esos niños llegaron a desarrollar conductas extremadamente masculinas, como para compensar la pérdida de sus padres" (p. 463).

En nuestro trabajo de investigación citado y del cual acabamos de extraer parte de la problemática de la uniparentalidad femenina, recogimos las opiniones vertidas por gente conocedora de lo que acontecía con las familias completas y uniparentales de su medio inmediato y comparamos sus opiniones sobre los hijos de unas y otras familias. Lo primero y más destacado que resulta de la indagación es el grado epidémico a que llega el número de hijos "problema" entre el sector más extenso de nuestras familias capitalinas: la tercera parte de familias encuestadas tiene por lo menos un hijo problema. En las familias incompletas por ausencia de padre, aumenta la probabilidad de tener hijos problema a razón de uno cada dos familias. Considerando tres clases de grandes problemas: los de bajo rendimiento o productividad, los de orden emocional o propiamente psiquiátrico y los de ajuste a la vida en común o de desviación social, los hijos problema uniparentalizados se agrupan en la segunda clase apareciendo como más sensibles a cuadros emocionales (entre las familias intactas los problemas son de rendimiento), sentando clara diferencia con la versión generalizada de propensión antisocial -que, naturalmente, hace suponer otro origen. La reducción de logros educacionales y ocupacionales también mencionados como efecto diferencial aparece en nuestro estudio como más característico de las familias completas, sugiriendo, igualmente, otro factor causal.

Estamos viendo hasta aquí que se reconocen efectos particulares en los hijos que son criados sin el concurso paterno. Sobre eso no faltaban dudas. Pero lo que siempre ha mantenido grado de certeza son las consecuencias por la falta materna. Desde el nacimiento del hijo hasta sus primeros años el rol de la madre es fundamental, sin dejar de ser importante más tarde. La pérdida de atención materna determina desarrollos no deseados para el hijo y son más desfavorables cuando más temprano sucedan. Estudios como los de Spitz han demostrado daños específicos por la separación de la madre particularmente en el lapso que corre del sexto al décimo-quinto mes de nacido el niño. El conjunto de síntomas que ocasiona forman el síndrome 
de "carencia afectiva infantil duradera" que engloba cuadros más conocidos como "hospitalismo" y "depresión analítica" entre una serie de transtornos "precoces" que van a diferenciarse de otros denominados "tardíos" que tendrán manifestaciones especialmente desde la adolescencia como rezago del carácter indeleble del padecimiento que ha tenido lugar en la infancia. En algunos casos estos efectos son discernibles, pero no es posible determinar causalidad unívoca a la ausencia de uno u otro de los padres ni tampoco separar lo determinante específico por la ausencia materna de lo que deriva por la disgregación familiar de la que al mismo tiempo puede ser efecto y causa. Y esta es la razón por la que los autores no sólo hacen referencia a la uniparentalidad sino al orden de problemas que se incluyen dentro del fenómeno mayor denominado disgregación familiar, que abarca otros problemas que pueden no tener la evidencia de la carencia paterna pero que pueden ocasionar mayores consecuencias, como puede darse con la enajenación mental de uno de ellos. Porot (1962) distingue tres clases de hogares presas de la disgregación: los hogares destruídos por el divorcio, el abandono y la muerte, los inexistentes (que no han pasado por un "estadio de pareja") y los hogares inestables con desequilibrios internos como los desacuerdos latentes, los de querella interminable, los que optan por evasiones, refugios y compensaciones que no hacen sino disfrazar una separación que es evidente a los hechos (que incluyen evasiones honrosas como la del trabajo en los hombre y la de obras sociales en las mujeres), los que instrumental izan al hijo y lo convierten en mediador precoz de la conflictiva paterna, etc.

Estas variedades de disgregación son producidas no solamente por motivos psicológicos que tienen expresión en la perturbación de las relaciones familiares sino por la gama de factores socio-familiares dependientes de las condiciones de vida como la pobreza, la guerra, la inmoralidad ambiental, la muerte de uno de los padres, particularmente de la madre, etc. Y lo que estos hechos ocasionan en los hijos, como afirma el mismo Porot, depende de la personalidad del hijo, de su edad, de su nivel de evolución afectiva tanto como de las condiciones en que se produce el fenómento disgregador y las fuerzas que hace entrar en juego. Ya se conoce que estos resultados pueden no ser inmediatos, y que si el curso de los acontecimientos abona en su favor pueden reactivarse después con 
imprevisibles consecuencias.

La incidencia de estas consecuencias en el componente emocional de los hijos es bastante extendida entre los autores. Mencionan, por ejemplo, "ausencia de reacción afectiva en el niño" (Levy), "inaptitud para dar o recibir afecto" (Lowrey), "incapaces de lazos afectivos sinceros" (Bowlby), "no tienen el menor sentido de los lazos afectivos humanos" (Behder y Yarnell), "fomentan reacciones de oposición" (Michaux), etc. Ya desde los cincuenta Heuyer (1962) resumía: "Todas estas disociaciones familiares tienen su repercusión en el desarrollo afectivo del niño; los odios familiares (Claude y Robin), las cargas domésticas (Heuyer), las reacciones múltiples de tipo depresivo con suicidio, de rebeldía, de malignidad, de evasión mística, fantasiosa o novelesca, son algunas formas de oposición del niño a este ambiente que ha llegado a ser desfavorable" (p. 163). Añadía la advertencia que debe recordarse siempre de que "la vida colectiva en la familia no basta para explicar las reacciones afectivas del niño". También desde esa época la Burlingham y Ana Freud (1964) encontraban "sentimientos incompletos e insatisfechos" (p. 29). Posteriormente Horney hablará de "carencia de afecto esencial" que determina las tres orientaciones fundamentales del carácter dirigidas: hacia la gente, contra la gente y fuera de la gente, con sus expresiones respectivas de impotencia, hostilidad y aislamiento como "normas inflexibles" de comportamiento. Estudiosos de nuestros años actuales como Wallon, Rheingold, Schaffer y Piaget detallan más sistemáticamente los efectos de las relaciones padrehijo en el sentido que estamos mencionando.

La referencia que orienta a los entendidos para registrar las expresiones de la uniparentalidad y la disgregación familiar es el supuesto ya axiomatizado de que la presencia de ambos padres en la familia es indispensable para la salud mental de los hijos, si bien no es requisito único. Se da por sentado que las condiciones para la formación integral de su personalidad parten del concurso complementario de los roles paterno y materno y que un déficit en esta relación de base es perjudicial para su desarrollo óptimo. Los estudios que hemos mencionado han tratado de precisar el tipo de -perjuicio ocasionado en la formación de la personalidad y es así mismo el tema del presente estudio, con la diferencia de que esta vez lo haremos a través del lente de un test de personalidad, uno de los tests 
más caracterizados de los del tipo de interpretación de formas, el de Rorschach.

\section{PSICODIAGNOSTICO RORSCHACH}

Se reconoce como parte de la metodología psicológica el uso de tests o reactivos que susciten comportamientos verificables en situaciones estandarizadas. Binet a principios de siglo otorgó carácter científico a estos procedimientos que se orientaron a desentrañar los secretos de la mente y de sus funciones particulares. Resultaron así y hasta la fecha dos grandes vías de indagación testológica, la cuantitativa y la cualitativa. La medida de la inteligencia fue la preocupación de quienes preferían las relaciones cuantitativas mientras que los otros se dedicaron a precisar los aspectos de la personalidad, que se conceptuaban descriptibles más que medibles. Entre los recursos de los que seguían por este último camino se contaba la prueba de las manchas de tinta sobre la que se venía experimentando largamente ${ }^{1}$, antes de que Hermann Rorschach la convirtiera en el test de diagnóstico de la personalidad por excelencia.

Las manchas de tinta constituyen el tipo de estímulo no estructurado que ecforiza en el sujeto que las interpreta sus propias configuraciones permitiendo que puedan compararse con las de otros. Se acepta entonces que cada examinado "proyecta" sus contenidos internos descubriendo las peculiaridades de su personalidad. Los contenidos proyectados pueden ser analizados desde diferentes puntos de vista y según el aspecto que interese al estudioso. Rorschach conocía el interés del psicoanálisis por develar las motivaciones inconscientes de lo percibido en las manchas, pero

1 Kerner en 1857, con 50 manchas disformes; el mismo Binet en 1895 apela a las manchas para auscultar "la imaginación visual"; Dearbon en Harvard en 1897 hace pruebas con láminas de manchas en series; Kirkpatrick en 1898 diferencia las respuestas a manchas de niños y adultos; en 1910 Whipple intenta estandarizar una serie de veinte láminas; en este mismo año Ribakoff en Rusia escribe sobre sus experimentos con ocho láminas, etc. (mayores referencias en Klopfer, J970, entre otros). 
prefirió centrar su análisis en la estructura de las respuestas o reacciones de los sujetos señalando de ese modo el camino para revertir el proceso proyectivo y encontrar los patrones psíquicos que lo determinan. Se podía auscultar así los distintos aspectos del campo psíquico individual haciendo de la prueba "un test pluridimensional" de la personalidad como lo define Beck (1967, p. 152).

Las diferencias individuales que resultan de la interpretación de estímulos ambiguos de las manchas no sólo describen peculiaridades de personalidad sino que además permite organizar éstas en tipologías caracterológicas (como introversivo - extraversivo) y patrones de comportamiento (primario-secundario) discernibles a su vez en orden a especialidades psicológicas como pueden ser los cuadros nosológicos en psicopatología y los perfiles de productividad en psicología del trabajo. $\mathrm{Su}$ aplicación trasciende incluso el ámbito de la psicología como lo atestiguan estudios de antropología, etnografía, medicina, etc.

El rango científico de la prueba se ha verificado al demostrarse sus recursos de validez, confiabilidad y sensibilidad que en su conjunto le ameritan una respetable cualidad de objetividad en tanto está constituyendo su propio cuerpo de conocimientos demostrables y de técnicas repetibles en el trabajo pericia!. Por su validez se ha probado la correspondencia entre sus índices diagnósticos y los exámenes clínicos así como otros datos del comportamiento de los examinados; su consistencia interna o confiabilidad ha sido igualmente verificada tanto por el procedimiento del test-retest, como por el de apareamiento entre resultados Rorschach y retratos de personalidad ante jueces, así como por la concordancia entre calificadores aislados sobre un mismo protocolo. Igualmente se ha demostrado su sensibilidad para discriminar modificaciones a cambios evolutivos (de estado y de situación) particularmente respecto a la edad, la enfermedad, la transculturación cualidad que tiene mucho uso en el diagnóstico de tipo antes-después. Estas condiciones del Rorschach son defendidas por un sinnúmero de estudios efectuados por especialistas reconocidos como Bohm, Klopfer, Beck, Morgen-thaler, Oberholtzer, Aisworth, Wittemborm y muchos otros más.

Uno de los aspectos de la prueba que de por sí le otorga buena dosis de 
objetividad es el hecho de que a tres cuartos de siglo de su aparición se conserva en lo esencial el método ideado por su autor. Su enriquecimiento, sin embargo, no ha cesado y a ello contribuyó el propio Rorschach. Una ligera reseña de los cambios que se incorporaban a la técnica señala los siguientes momentos:

- Rorschach y Behn Eschenburg, en 1921, elaboran la serie paralela que lleva las sílabas iniciales de sus nombres, el Bero test.

- Furrer, en 1925, comienza el desarrollo de las respuestas de movimiento, y Binder, en 1932, las de claroscuro.

- En 1937 Beck publica su "Introducción al método de Rorschach, con las contribuciones de Benjamín y Lopfer. Este último publica la revista trimestral Rorschach research exchange desde 1936 y tres después funda el Rorschach Institute.

- La técnica se difunde en 1939 y es aplicada para la selección de oficiales que serían enviados al frente durante la segunda gran guerra. Esta misma circunstancia lleva al uso de la técnica en gran escala y en 1941 Harrower y Erickson comienzan el procedimiento de la administración colectiva. En este mismo año tiene lugar el primer Congreso de Rorschach. Todo esto en los Estados Unidos de Norteamérica.

- En Francia y por los cuarenta Ombredane y Mme. Canivet reorganizan la simbología de calificación adoptando aportes norteamericanos y suizos. En suiza desarrolla un fuerte movimiento rorschachiano y la técnica se asimila en otros países incluyendo Inglaterra con Eysenck.

- Grossi y Levine elaboran el Rorschach gráfico donde el interrogatorio es reemplazado por el dibujo de las respuestas que luego dará lugar al protocolo de localización.

- Ya pasando el medio siglo se estudian modificaciones en el número de manchas, particularmente el Z Test de Zulliger, que reduce la prueba a tres láminas, y el Test de Holtzman de 45 láminas y la consigna de una respuesta por lámina.

- En Estados Unidos yen 1974 aparece el primer tomo de la obra de Exner que presenta una reestructuración de la técnica conocida a la fecha como sistema comprensivo, que es la que emplearemos en el presente trabajo. 


\section{Estudios Rorschach en la infancia:}

El mismo Rorschach inició las observaciones del comportamiento infantil ante las manchas de tinta y previno de la necesidad de considerar las diferencias con los adultos, particularmente respecto de las frecuencias de las respuestas, el incremento de respuestas de animales, la tendencia concretizadora de las respuestas globales y la reducción de las respuestas de movimiento. Los autores que le sucedieron han sido cautelosos desde entonces en la interpretación de los protocolos de niños y han seguido dos caminos en sus estudios para recordar esas diferencias; "los dirigidos a establecer listas de puntajes para aquellas variables de frecuencia determinada y los que presentan las normas por edad para todas las variables" (Ames, 1961, p.37).

Nuestro trabajo se inscribe en el segundo camino que Ames modeló por los años cincuenta analizando un conjunto de 650 protocolos distribuidos entre 25 varones y 25 niñas para cada uno de los trece niveles de edad de 2 a 10 años con intervalos de seis meses y un año, referidos a niños previamente diagnosticados de capacidad intelectual media pertenecientes al estrato social medio de Connecticut, Estados Unidos. Sigue la técnica suiza y el modelo Rorschach de cómputo y plantea cuatro objetivos: caracterizar la técnica de administración de la prueba en niños, establecer normas de las variables del Rorschach por edad, presentar protocolos de casos ilustrativos para cada edad y relacionar el punto de vista evolutivo y la puntuación en la técnica proyectiva. Ames resume su propósito diciendo: "Parece probable que las técnicas proyectivas, si se aplican cuidadosamente y se interpretan con habilidad, teniendo en cuenta las normas adecuadas para cada edad, pueden iluminar cada uno de los tres factores siguientes: 1) nivel de desarrollo del niño, 2) individualidad innata y 3) tipo de adaptación que está realizando a su situación vital" (Ames, 1961, p. 16). En su obra Ames hace una excelente revisión de los trabajos sobre niños que le antecedieron y se plantea una metodología rigurosa que incluye técnicas de validez y confiabilidad. En sus resultados nos ofrece tablas por grupos de edad, listas de detalles normales de formas positivas $(\mathrm{F}+)$ y formas populares por cada lámina, así como promedios de variables Rorschach en 
los trece grupos de edad, además de percentiles, mediana y cuartiles de las principales variables por edad.

Halpern (1953), también en la década del 50, emprende en Inglaterra su estudio de orden clínico sobre 40 casos de niños entre 2 años y 9 meses y 10 años 6 meses, clasificados en problemas de ajuste, disturbios emocionales, trastornos del sistema nervioso central, esquizofrenia y retardo mental. Establece casos tipo para cada desorden y los interpreta según el método psicodinámico alrededor de factores de personalidad centrales como el autoconcepto y la identificación, la ansiedad, mecanismos de defensa y fuerzas del yo. Así mismo señala pautas para administrar el test a niños preescolares e indica que la aplicación a los escolares es semejante al de los adultos. Es esencial su recomendación de que las normas del test por edad no deben quedar en frecuencias y porcentajes "sino que hay que interpretar estas normas en términos de factores del desarrollo y funcionamiento dinámico de la personalidad" (Halpern, 1953, p. 2). Se orienta por la técnica de Klopfer pero simplifica el cómputo al modo de Rorschach y Beck

A comienzos de la década del 60, Beizman (1968) en París, investiga a los niños entre 2 años nueve meses y 10 años: "Nos hemos propuesto ver en qué se diferencia el niño y cómo se encamina hacia la edad adulta, lo cual se descubre a través del Rorschach por medio de los índices de madurez tanto afectiva como mental". Al mismo tiempo Beizman se propone precisar los rasgos característicos de la "mentalidad infantil" en el Rorschach así como hacer "el examen crítico de los factores del Rorschach profundizando en sus significaciones". Su muestra consta de 400 protocolos de niños y niñas a un promedio de 40 por edad. Su método sigue los principios básicos de Rorschach en la terminología francesa e introduce en la administración la técnica gráfica para obtener la localización de las respuestas: se pide al sujeto "una reproducción por copia sobre la misma lámina, de la porción espacial interpretada (con ayuda de un papel transparente)" (Ob. Cit., p. 30). Su procedimiento de interpretación parte de los datos sobresalientes positivos y negativos para obtener la estructura mental o funcionamiento cognitivo y la estructura afectiva, sintetizando su incidencia en conclusiones descriptivas. Es de relevar su análisis y significación de las diversas formas de aprehensión de las localizaciones, 
llegando a establecer el nivel genético de la estructuración perceptiva de las respuestas globales, de detalle, pequeño detalle y espacio en blanco. Igualmente efectúa un trabajo minucioso en el análisis de los determinantes y expone el carácter evolutivo por cada grupo de edad, llegando a cumplir su objetivo de ofrecer los caracteres de la mentalidad infantil en la prueba.

En la década del 70, en Estados Unidos, John Exner examina una amplia muestra de protocolos conseguida con la colaboración de doscientos examinadores, en donde se cuentan la suma de 2,545 protocolos de niños y adolescentes entre 5 y 16 años clasificados en tres grupos: no paciente, problemas de conducta y retraídos, distribuidos en varios niveles socioeconómicos $\mathrm{y}$, de todos los cuales presenta sus promedios y desviaciones estándar. En su publicación de 1978 aparecen las normas Rorschach para las edades mencionadas, separándolas de las que corresponden a los adultos. En su publicación de 1982 complementa sus estudios anteriores y expone los resultados de una nueva muestra de 1870 protocolos administrados por 147 examinadores de niños normales entre 5 y 16 años. Allí amplía su escala de extracción socioeconómica a nueve categorías (tres por cada estrato alto, medio y bajo), las mismas que las zonas geográficas, particularmente urbana y rural. Ofrece tablas de datos normativos para cada edad y los promedios y desviaciones estándar y frecuencia de aparición de 49 variables Rorschach. Así mismo establece diferencias por sexo, nivel socioeconómico y área geográfica.

En este segundo estudio, además, realiza un seguimiento longitudinal con el Rorschach aplicado a 59 sujetos, a los 8, 10, 12 y 14 años (retest cada dos años) para complementar la interpretación de los datos normativos. Igualmente, presenta casos de niños y adolescentes normales frente a casos de niños con problemas de depresión, esquizofrenia y problemas de aprendizaje. En el laborioso estudio se leen aportaciones teóricas interesantes en relación a la naturaleza del Rorschach en tanto, por ejemplo, otorga mayor fiabilidad a las interpretaciones y deducciones hipotéticas que derivan del sumario estructural, frente a la interpretación derivada del contenido o asociación libre, de la encuesta y de las secuencias de la valoración, cargadas de materia especulativa. 
Tan importante estudio tuvo que derivar en una técnica especial que describimos en breve.

En 1984, en Argentina, Vera Campo sigue el sistema comprensivo de Exner y se esfuerza en integrarlo al enfoque dinámico psicoanalítico, aplicándolo especialmente al área del diagnóstico clínico infantil. Es así como nos ofrece observaciones de problemas y casos que se presentan a menudo entre los niños. Pero no se queda sólo en eso, al mismo tiempo trata de los problemas técnicos y teóricos relacionados con el uso del Rorschach. Basada en su experiencia recomienda su aplicación desde los cuatro o cinco años de edad donde es posible ya descripciones de personalidad así como del desarrollo perceptivo, afectivo y de pensamiento.

Como se comprende, los protocolos de Vera Campo corresponden a niños latinos y entre los 4 y los 12 años, sobre los cuales enfatiza en el valor diagnóstico y pronóstico haciendo uso detallado de la técnica del retest y dándole aplicación útil para la guía del tratamiento por medio de la comparación entre las referencias de Exner y los resultados concretos de sus casos. En el mismo camino, demuestra también la utilidad del Rorschach en el estudio comparativo de la evolución infantil.

Dos aportes resaltan en la obra de Campo, uno es incluir el aspecto formal a las respuestas de movimiento inanimado (m) en el sistema comprensivo, y otro es enriquecer la interpretación del movimiento animal (FM), dándole un valor diagnóstico de comportamiento fóbico en la infancia. Además, y con ilustraciones de casos clínicos, analiza los signos de la depresión y tendencia al suicidio de Exner y otros autores en niños entre 5 y 11 años. Alcanza así mismo a estudiar casos de niños con trastornos de aprendizaje, acercándose al establecimiento de nexos entre la inteligencia y la personalidad, y extiende la utilidad de la prueba para casos de manifestaciones psicosomáticas y cuadros afines en la casuística infantil.

\section{Sistema comprensivo de Exner:}

El sistema propuesto por Exner es una manera particular de trabajar con el 
Rorschach que nosotros acogemos por que brinda referencias que dan mayor seguridad en las tareas de calificación e interpretación de las respuestas, ahorrándonos de caer mayormente en las dudas que siempre suscitan las pruebas de interpretación de formas. Una caracterización del sistema comprensivo destacaría los siguientes puntos:

a) Fidelidad al método Rorschach, en el sentido de empleo del mismo material y la misma técnica de codificación y análisis psicológico. Las modificaciones que introduce deben considerarse como aportaciones al método.

b) Procura integrar en un lenguaje común lo mejor de cada sistema de trabajo reconocido internacionalmente: Beck, Klopfer, Hertz, Piotrowsky, Rapaport y Shafer.

c) La elaboración del sistema se basa en datos empíricos y de investigación experimental y muestra especial dedicación por acompañar con su respectivo criterio de prueba cada afirmación que sostiene.

d) Mantiene un proceso constante de revisión e investigación no solamente para efectos de comprobación de hipótesis sino también para registrar los posibles cambios que derivan por razones de evolución y de condiciones sociales y culturales.

e) La particularidad de tratamiento de datos del sistema hace que se afronten de mejor manera los problemas de validez y confiabilidad, en razón de su preocupación constante por verificar las bases de cada nueva formulación de procedimiento o de interpretación y de revisar las particularidades intrínsecas de la prueba,

f) Por su fidelidad al método Rorschach no pretende plantear una base teórica determinada ni como fundamento de la prueba ni como desarrollo singular. Como el método lo establece se atiene a la relación de significado y significante.

g) La orientación de la interpretación es global, en el sentido comprensivo y holístico.

h) Los procedimientos que introduce en el trabajo de elaboración de las respuestas facilita el aprendizaje del test y previene de dudas y especulaciones, $\mathrm{y}$

i) Limita la influencia del examinador, tanto en la administración como 
en el tratamiento de las respuestas.

La administración de la prueba sigue básicamente el procedimiento tradicional propuesto por Rorschach, salvo la recomendación de ubicación del examinador que debe colocarse a un costado del probando, por haberse comprobado que en otras posiciones aquel influye determinantemente sobre éste

En las páginas siguientes mostramos los símbolos de valoración, las áreas de interpretación y el resumen estructural que muestran en conjunto el orden propuesto por el sistema comprensivo, el cual nos guía para el encuentro de la personalidad de los niños de familias uniparentales que tenemos como objetivo.

\section{SIMBOLOS DE VALORIZACIÓN}

1. Localización:

Global: W

Detalle: D

Pequeño detalle: Dd

Espacio blanco: $\mathrm{S}$

Calidad evolutiva:

$\begin{array}{ll}\text { Sintetizada } & + \\ \text { Ordinaria } & \mathrm{o} \\ \text { Vagas } & \mathrm{V} \\ \text { Negativas } & -\end{array}$

2. Determinantes:

Formas: $\mathrm{F}$

Movimiento:

Humano: $\mathrm{M}$

Animal: FM

Inanimado: $m$

Dimensión activa-pasiva a/p

Color cromático: FC, CF,C,Cn

Color acromático: FC',C'F,C'

Sombreado textura: FT,TF, T

Sombreado vista: FV, VF, V

Sombreado difuso: FY, YF, Y

Respuesta Par:

(2)

Respuesta de reflejo: Fr, $\mathrm{rF}$

Respuesta forma dimensión: FD
Calidad Formal: $\quad$ Superior + Ordinario o

Débil w

Negativa -

3. Contenidos:

$\mathrm{H},(\mathrm{H}), \mathrm{Hd},(\mathrm{HD}), \mathrm{A},(\mathrm{A}), \mathrm{Ad},(\mathrm{Ad}), \mathrm{Ab}$, (Ab), Al, An, Art, Ay, Bt, Bl, Cg, Cl, Fi, $\mathrm{Fd}, \mathrm{Ge}, \mathrm{Hb}, \mathrm{Ls}, \mathrm{Na}, \mathrm{Sx}, \mathrm{Xy},(\mathrm{Vo})$.

4. Frecuencia

Popular: P

(Lista de 13 respuestas)

5. Actividad organizativa:

$\mathrm{Z}$

$\mathrm{Zf}$ ( frecuencia)

Zd ( diferencia de Zest y Suma Z)

6. Valoraciones especiales:

Verbalizaciones desviadas: DV

Combinaciones inapropiadas: INCOM

FABCOM, CONTAM

Logica inapropiada: ALOG

Otras: PSV, MOR, CP. 


\section{ÁREAS INTERPRETATIVAS}

1. Área de validez:

1) Número de respuestas $R$

2) LAMBDA L

3) Actividad organizativa $\mathrm{Zd}+-3$

2. Área de control, tolerancia al estrés y estilo de vida:

1) Experiencia básica $\quad$ EB

2) Experiencia potencial ep

3) Experiencia actual EA

4) Experiencia de los estímulos es

5) Índice de tolerancia al estrés D

6) Índice de ajuste Adj. D

7) Respuestas de forma- dimensión FD

3. Área del sistema cognitivo-productivo

1) Complejidad e iniciativa cognitiva creativa:

-Actividad organizativa: Zf, Zd.

-Distribución de la localización:

W, D, Dd, S

-Habilidad y potencial creativo:

$\mathrm{M}, \mathrm{FM}, \mathrm{m}$

2) Rigidez y pobreza cognitiva:

-Dimensión activo-pasivo

-Perseveraciones PSV

-Confabulaciones

CONFAB

3) Exactitud perceptiva y

convencional:

- Respuestas populares

-Calidad formal

$$
\begin{aligned}
& \mathrm{P} \\
& \mathrm{X}+\%
\end{aligned}
$$

F+\%
FQx
FQf
X-\%

4) Características del pensamiento:

-Relación a/p, Ma/MP

-Calidad y relación $\mathrm{M}$

-Especiales puntajes críticos:

WSUM 6

DV,INCOM

DR, FABCOM

ALOG. CONTAM

4. Área del sistema afectivo:

1) Externa: Proporción FC; $\mathrm{CF}+\mathrm{C}$

Índice de Responsividad Afectiva Afr

Proyección al color CP

Determinantes múltiples DM

2) Interna: e, T, Y, V

Respuesta en blanco $\mathrm{S}$

3) Respuestas de agresividad: AG

5. Área de autoimagen y actitudes interpersonales:

1) Percepción de sí mismo:

Índice de egocentricidad $3 r+(2) 1 R$

Contenido mórbido MOR

Respuestas personales PER

Índices intelectuales $\mathrm{An}+\mathrm{Xy}$

6. Indices psicopatológicos:

(No se incluyen en el presente trabajo)

\section{PLANTEO Y PROCEDIMIENTO:}

Estamos en el rastro de la salud mental de los hijos de familias uniparentales y en los efectos que produce la carencia de uno de los padres. Trabajamos dentro de la hipótesis general de que en relación con los hijos de las familias intactas aquellos arrastran una secuela psíquica por efecto 
específico de la condición carencial de su crianza. Venimos siguiendo este asunto desde 1994 cuando en uno de nuestros estudios citados encontramos que, p.ej., la secuela que predomina apunta más a problemas psiquiátricos que a trastornos de conducta.

Los hijos que se crían con sólo uno de los padres sufren efectos específicos que se registran o expresan en el comportamiento, o, lo que es igual, muestran huella en su personalidad, huella de defecto, de problema personal. Esta diferencia con respecto a los hijos de familias completas, pude ser captada entre otros medios por los tests de personalidad como Psicodiagnóstico de Rorschach que como acabamos de ver contiene una serie de indicadores a través de cuyo ordenamiento es posible registrar variaciones. La serie de variables Rorschach se combinan de formas diferentes según cada propuesta de los autores y nosotros optamos aquí por la presentación de Exner en su resumen estructural del punto 2.2.3. En este entendido, podemos precisar algo más la hipótesis que nos guía y proponer que los indicadores Rorschach de protocolos de hijos de familias uniparentales tienen diferencias significativas respecto de los protocolos de hijos de familias completas.

Se plantea así un estudio de comparación y contraste entre un grupo experimental y uno de control por mediación de un test de personalidad. Se complementará el procedimiento con técnicas pertinentes como la de interpretación y la de verificación estadística significativa a través del paquete SPSS V.4.O. aplicado en el Instituto de Investigaciones Psicológicas de nuestra Facultad.

Como hemos venido diciendo, el objetivo de nuestro trabajo es tratar de precisar los aspectos de personalidad que se sensibilizan en los niños por efecto de su crianza con un solo padre. Esperamos que la mediación del Psicodiagnóstico de Rorschach trace un nuevo canal de esclarecimiento y diferenciación respecto de la influencia de los roles paterno y materno en la familia.

La obtención de los protocolos corrió a cargo de los autores del trabajo y una decena de alumnos del último año de la carrera de psicología que llevaban en su momento la asignatura de Rorschach y a quienes se entrenó de modo especial para el efecto. Hemos visitado centros escolares y domicilios particulares en busca de niños de ambos tipos de familia, 
encontrando cierta dificultad para contar con familias uniparentales dispuestas. La aplicación individual de la prueba y nuestra disponibilidad alargó el trabajo de acopio de protocolos en el primer semestre de 1995. La muestra resulta así a criterio, y al alcance del grupo de examinadores que se dispersó por toda la ciudad en la idea de hacer lo más azaroso la elección de probandos.

La aplicación del test sigue la técnica de estándar de administración con las recomendaciones propuestas por Exner, según ya adelantamos. Luego de la recopilación de protocolos se procedió a la calificación o valoración de las respuestas, y en ello se tuvo cuidado de efectuar dos revisiones a cargo de los autores. Sigue la elaboración del resumen estructural que nos exigió igual cuidado de revisión y, por último la codificación de categorías y frecuencias del resumen estructural y de los datos de los probandos para disponer la base de datos de donde se obtendrá por procesamiento automático las estadísticas de tendencia central y de diferenciación quenecesitamos para cumplir con las propuestas de nuestro trabajo.

En la sección de anexos ofrecemos las referencias que detallan algo más el procedimiento seguido para especificar los datos pertinentes a nuestra propuesta.

Sobre la base del resumen estructural así como la codificación de sus frecuencias y categorías puede derivarse el perfil Rorschach perteneciente a un sujeto o grupo y permitir su comparación con otro. Es precisamente el perfil de niños pertenecientes a familias incompletas lo que se debe obtener del conjunto de protocolos para confrontarlo con el que resulta de los protocolos de niños procedentes de familias completas.

El orden de variables que vamos a comparar entre unos niños y otros sigue la secuencia del resumen estructural presentado en el punto 2.2.3.

\section{RESULTADOS}

\section{Muestra:}

Hemos comprometido a 223 familias, en cada una de las cuales se ha examinado a un niño. Los hijos de familias incompletas suman 60 divididos por el sexo en dos mitades exactas y en el trabajo cumplen el papel de grupo de estudio. El otro grupo de niños nos sirve de control y suman 163 
divididos en 81 niñas y 82 varones. En uno y otro grupo el mayor número de niños se halla comprendido entre 9 y 10 años en señal de edad representativa de la niñez (en el Anexo se incluye el baremo Rorschach de Lima para ambas edades, obtenido en un trabajo nuestro anterior) y van escoltados por un número mucho menor de 8 y 11 años, como puede leerse en el cuadro 1. La extracción social de todos los niños es básicamente popular y en ningún caso excede el nivel de la clase media.

\section{Cuadro 1}

\section{Características de la muestra}

\begin{tabular}{|c|c|c|c|c|c|c|c|}
\hline \multirow{2}{*}{ Edad } & \multicolumn{3}{|c|}{ De familia uniparental } & \multicolumn{3}{|c|}{ De familia completa } & \multirow{2}{*}{ Total } \\
\hline & Varones & Niñas & Total & Varones & Niñas & Total & \\
\hline 8 & 5 & 5 & 10 & 7 & 7 & 14 & 24 \\
\hline 9 & 10 & 10 & 20 & 38 & 35 & 73 & 93 \\
\hline 10 & 10 & 10 & 20 & 30 & 31 & 61 & 81 \\
\hline I1 & 5 & 5 & 10 & 7 & 8 & 15 & 25 \\
\hline Total & 30 & 30 & 60 & 82 & 81 & 163 & 223 \\
\hline
\end{tabular}

Total: Varones 112

Niñas 111

Por otro lado, se ha tenido cuidado de incluir en uno y otro grupo solamente a niños que cursaban su escolaridad normal y el nivel correspondiente a su edad (ni retrasados ni con problemas de conducta manifiestos), con el fin de que la homogeneidad entre los grupos sea lo más próxima y quede en juego únicamente la variable que nos interesa. A ello apunta también la equiparidad de número por el sexo de los niños.

\section{Indicadores significativos:}

En la tabla 1 presentamos las variables Rorschach en uno y otro grupo de protocolos, sus valores $\boldsymbol{t}$ diferenciales y el nivel de significación que alcanzan. De allí extraemos sólo las variables significativas hasta el nivel de .05 , que las reunimos en la tabla 2 y que representan el resultado cuantitativo de nuestro trabajo. Vemos en él quince variables que difieren significativamente de uno a otro grupo de niños $(\mathrm{C}$ y $\mathrm{U})$ y por ahora 
conviene hacer referencia a su interpretación psicológica o a su significación cualitativa.

En el sistema comprensivo de Exner el símbolo 2 denota la actividad organizativa o la aptitud para relacionar y organizar las partes de la mancha de un modo significativo. El examinado combina las percepciones que tiene de la mancha en una percepción única y con significado original. Tres son las puntuaciones $\mathrm{Z}$ : $\mathrm{Z} f$ es el número de $\mathrm{Z}$ que aparece en el protocolo completo, Sum $Z$ es la suma de los puntajes asignados a cada valor $\mathrm{Z}, \mathrm{y} \mathrm{Zd}$ es la diferencia de la sumatoria de $\mathrm{Z}$ menos el $\mathrm{Z}$ esperado y consignado en tabla especial; esta diferencia se estima normal entre +3 y 3. En niños de 5 a 7 años de edad es normal que aparezca $Z d-3$ que se considera causada por un excesivo motivo de logro que no puede ser alcanzado.

$\mathrm{Z} f$ viene a ser como una representación compleja del intelecto y ofrece "un indicio referente al grado en que el sujeto es capaz de organizar el campo de los estímulos, esfuerzo intelectual por dar sentido a los estímulos, capacidad de analizar, y sintetizar". Es indicador de las operaciones cognitivo-perceptivas y de cómo éstas se integran en la realidad cognitiva de la persona; representa la energía asociativa o la iniciativa cognitiva como esfuerzo intelectual y disposición para enfocar con objetividad el análisis de los estímulos externos. Traduce una representación compleja de la inteligencia.

Cuando $\mathrm{Z} f$ es bajo significa limitación intelectual o poco interés en enfrentar la complejidad del estímulo; pero cuando es alto denota esfuerzo intelectual o disposición para tratar más cuidadosamente el campo de los estímulos.

El símbolo $W$ representa las respuestas globales o las que interpretan la totalidad de la mancha presentada "en un solo acto de percepción". Desde Rorschach se consideran como índice de energía disposicional para la actividad asociativa y también como expresión de la voluntad consciente o inconsciente de alcanzar complicados rendimientos en los que se comprometen procesos de abstracción o combinación (Rorschach, 1967, p. 59). Así mismo indican "afán de superación" y "voluntad de rendimiento". Más que la aptitud efectiva. 
Tabla 1

Comparación de las variables Rorschach y sus niveles de significación entre los grupos de protocolos de niños de familias completas $(C)$ y uniparentales (U).

$\mathrm{C}=$ No $163 \mathrm{U}=$ No 60

\begin{tabular}{|c|c|c|c|c|c|c|}
\hline \multirow{2}{*}{ Variables } & \multicolumn{2}{|c|}{$x$} & \multicolumn{2}{|c|}{ DS } & \multirow{2}{*}{ "t" } & \multirow{2}{*}{$\begin{array}{c}\text { Nivel de } \\
\text { Significación }\end{array}$} \\
\hline & C & U & C & U & & \\
\hline $\mathrm{R}$ & 20.55 & 20.83 & 8.63 & 7.60 & -0.22 & 0.81 \\
\hline $\mathrm{Zf}$ & 7.63 & 9.20 & 4.39 & 4.32 & -2.39 & ${ }^{*} 0,01$ \\
\hline$p$ & 4.63 & 4.65 & 2.11 & 1.88 & -0.06 & 0.95 \\
\hline (2). & 7.12 & 7.23 & 4.74 & 4.04 & -0.17 & 0.86 \\
\hline W & 5.02 & 6.82 & 2.80 & 3.82 & -3.83 & ${ }^{*} 0,00$ \\
\hline$D$ & 11.48 & 10.28 & 7.11 & 6.06 & 1.16 & 0.21 \\
\hline $\mathrm{Dd}$ & 3.89 & 5.28 & 3.40 & 10.03 & 1.55 & 0.29 \\
\hline$S$ & 1.37 & 1.50 & 1.73 & 1.52 & -0.52 & 0.58 \\
\hline $\mathrm{DQ}+$ & 2.29 & 2.40 & 2.75 & 2.48 & -0.26 & 0.79 \\
\hline Dq o & 11.61 & 11.48 & 5.43 & 5.35 & 0.16 & 0.87 \\
\hline $\mathrm{DQ} v$ & 2.69 & 2.57 & 2.99 & 2.52 & 0.28 & 0.76 \\
\hline $\mathrm{DQ}$ - & 3.81 & 4.18 & 3.22 & 2.98 & -0.78 & 0.42 \\
\hline $\mathrm{FQ}+$ & 0.72 & 0.32 & 1.44 & 0.79 & 2.67 & ${ }^{*} 0,00$ \\
\hline FQ o & 13.18 & 13.20 & 6.29 & 6.29 & -0.02 & 0.98 \\
\hline $\mathrm{FQ} v$ & 1.90 & 2.18 & 1.65 & 1.73 & -1.14 & 0.26 \\
\hline$F Q$ - & 3.93 & 4.33 & 3.35 & 2.93 & -0.88 & 0.38 \\
\hline FQf + & 0.17 & 0.05 & 0.56 & 0.22 & 2.22 & ${ }^{*} 0,02$ \\
\hline FQfo & 8.58 & 8.92 & 4.66 & 5.05 & -0.45 & 0.65 \\
\hline FQf v & 1.26 & 1.33 & 1.25 & 1.48 & -0.35 & 0.72 \\
\hline FQf - & 2.96 & 3.40 & 2.81 & 2.87 & -1.03 & 0.3 \\
\hline$M Q+$ & 0.32 & 0.18 & 0.71 & 0.62 & 1.31 & 0.19 \\
\hline$M Q \circ$ & 1.18 & 1.15 & 11.47 & 1.39 & 0.13 & 0.89 \\
\hline$M Q v$ & 0.11 & 0.18 & 0.31 & 0.50 & -1.05 & 0.29 \\
\hline$M Q$ - & 0.31 & 0.20 & 0.82 & 0.55 & 1.12 & 0.26 \\
\hline DM & 1.22 & 1.17 & 1.98 & 1.77 & 0.2 & 0.84 \\
\hline$M$ & 1.69 & 1.70 & 1,877 & 1.98 & -0.04 & 0.96 \\
\hline FM & 2.58 & 2.22 & 2.79 & 1.98 & 1.09 & 0.27 \\
\hline$M$ & 0.50 & 0.78 & 0.94 & 1.48 & -1.39 & 0.16 \\
\hline $\mathrm{C}+\mathrm{Cn}$ & 0.28 & 0.17 & 0.81 & 0.59 & 1.11 & 0.27 \\
\hline CF & 0.63 & 1.03 & 0.94 & 1.37 & -2.1 & ${ }^{*} 0,03$ \\
\hline FC & 0.71 & 0.58 & 1.07 & 1.12 & 0.73 & 0.46 \\
\hline $\mathrm{FC}+\mathrm{CF}+\mathrm{C}$ & 0.53 & 0.43 & 1.26 & 0.87 & 0.67 & 0.5 \\
\hline
\end{tabular}




\begin{tabular}{|c|c|c|c|c|c|c|}
\hline \multirow[b]{2}{*}{ Variables } & \multicolumn{2}{|c|}{$X$} & \multicolumn{2}{|c|}{ DS } & \multirow[b]{2}{*}{ "t" } & \multirow{2}{*}{$\begin{array}{c}\text { Nivel de } \\
\text { Significación }\end{array}$} \\
\hline & C & U & C & U & & \\
\hline $\mathrm{FT}+\mathrm{TF}+\mathrm{T}$ & 0.52 & 0.18 & 0.96 & 0.43 & 2.63 & ${ }^{*} 0,00$ \\
\hline$F Y+Y F+Y$ & 0.29 & 0.3 & 0.69 & 0.59 & -0.06 & 0.95 \\
\hline$F V+V F+V$ & 0.04 & 0.06 & 0.23 & 0.25 & -0.64 & 0.52 \\
\hline FD & 0.17 & 0.31 & 0.42 & 0.7 & -1.87 & 0.06 \\
\hline $\mathrm{F}$ & 12.87 & 14.53 & 6.85 & 10.86 & -1.36 & 0.17 \\
\hline $\mathrm{Fr}+\mathrm{F}$ & 0.04 & 0.05 & 0.23 & 0.28 & -0.21 & 0.83 \\
\hline $\mathrm{H}$ & 4.52 & 4.1 & 3.44 & 2.7 & 0.86 & 0.39 \\
\hline$A$ & 11.52 & 11.7 & 5.66 & 4.3 & -0.22 & 0.82 \\
\hline $\mathrm{Bt}$ & 0.83 & 1.35 & 1.23 & 1.52 & -2.64 & ${ }^{*} 0,00$ \\
\hline $\mathrm{Fi}$ & 0.15 & 0.36 & 0.73 & 1.22 & -1.94 & ${ }^{*} 0,05$ \\
\hline $\mathrm{Hb}$ & 0.37 & 0.63 & 0.66 & 1 & -2.22 & ${ }^{*} 0,02$ \\
\hline PSV & 0.92 & 1.5 & 1.93 & 1.85 & -1.99 & ${ }^{*} 0,04$ \\
\hline DV & 0.2 & 0.48 & 0.62 & 0.93 & -2.53 & ${ }^{*} 0,01$ \\
\hline INCOM & 0.83 & 0.93 & 1.36 & 1.44 & -0.47 & 0.63 \\
\hline FABCOM & 0.48 & 0.8 & 0.95 & 1.31 & -1.98 & ${ }^{*} 0,04$ \\
\hline CONTAM & 0.01 & 0 & 0.15 & 0 & & \\
\hline ALOG & 0.21 & 0.48 & 0.61 & 1 & -2.47 & ${ }^{*} 0,01$ \\
\hline MOR & 0.6 & 0.78 & 1.14 & 1.63 & -0.97 & 0.33 \\
\hline $\mathrm{Zd}$ & -0.51 & -1.64 & 3.52 & 4.71 & -1.93 & ${ }^{*} 0,05$ \\
\hline Sum C & 1.46 & 1.59 & 1.75 & 1.62 & -0.52 & 0.6 \\
\hline $\mathrm{EA}$ & 3.23 & 3.57 & 2.71 & 2.21 & -0.78 & 0.43 \\
\hline $\mathrm{Ep}$ & 4.81 & 4.05 & 4.74 & 3.32 & 1.14 & 0.25 \\
\hline A & 3.25 & 3.27 & 2.68 & 2.62 & -0.05 & 0.95 \\
\hline$P$ & 1.69 & 1.6 & 1.88 & 1.811 & 0.31 & 0.75 \\
\hline $\mathrm{Ma}$ & 1.29 & 1.22 & 1.64 & 1.44 & 0.3 & 0.76 \\
\hline $\mathrm{Mp}$ & 0.6 & 0.53 & 0.99 & 0.89 & 0.51 & 0.61 \\
\hline $\mathrm{L}$ & 3.5 & 3.83 & 5.98 & 5.18 & 0.38 & 0.7 \\
\hline $\mathrm{F}+\%$ & 68.63 & 65.31 & 18.05 & 17.48 & 1.23 & 0.22 \\
\hline$X+\%$ & 68.22 & 76.95 & 16.03 & 18.23 & -1.21 & 0.22 \\
\hline $\mathrm{A} \%$ & 56.72 & 57.48 & 19.51 & 15.92 & -0.27 & 0.78 \\
\hline Afr & 0.56 & 0.53 & 0.22 & 0.18 & 1.01 & 0.31 \\
\hline $3 r+(2) / R$ & 0.36 & 0.37 & 0.19 & 0.16 & -0.31 & 0.775 \\
\hline XTRAcro & 18.33 & 14.48 & 15.21 & 10.69 & 1.88 & 0.007 \\
\hline XTRCro. & 20.09 & 15.85 & 18.35 & 11.01 & 1.68 & 0.09 \\
\hline $\mathrm{M}+\mathrm{y}$ & 0.31 & 0.27 & 0.8 & 0.63 & 0.64 & 0.73 \\
\hline Sum Z & 21.72 & 26.73 & 13.87 & 15.64 & -2.31 & 0.03 \\
\hline
\end{tabular}


Tabla 2

Resumen de las variables Rorschach con diferencias significativas entre niños de familias completas $(C)$ y de familias uniparentales $(U)$.

\begin{tabular}{|c|c|c|c|c|c|c|}
\hline \multirow{2}{*}{ Variables } & \multicolumn{2}{|c|}{$\mathrm{X}$} & \multicolumn{2}{|c|}{ D.S. } & \multirow{2}{*}{$" t "$} & \multirow{2}{*}{$\begin{array}{r}\text { Nivel de. } \\
\text { Significac. }\end{array}$} \\
\hline & C & $\mathbf{U}$ & C & $\mathbf{U}$ & & \\
\hline $\mathrm{Zf}$ & 7.63 & 9.20 & 4.39 & 4.32 & -2.39 & 0.01 \\
\hline Sum.Z & 21.72 & 26.73 & 13.87 & 15.64 & -2.31 & 0.03 \\
\hline $\mathrm{Zd}$ & -0.51 & -1.61 & 3.52 & 4.71 & -2.67 & 0.00 \\
\hline W & 5.02 & 6.82 & 2.80 & 3.82 & -3.83 & 0.00 \\
\hline FQf+ & 0.17 & 0.05 & 3.56 & 0.22 & 2.22 & 0.02 \\
\hline FQx+ & 0.72 & 0.32 & 1.44 & 0.79 & 2.67 & 0.00 \\
\hline $\mathrm{CF}$ & 0.63 & 1.03 & 0.94 & 1.37 & -2.10 & 0.03 \\
\hline $\mathrm{FT}+\mathrm{TF}+\mathrm{T}$ & 0.52 & 0.18 & 0.96 & 0.43 & 2.63 & 0.00 \\
\hline BT & 0.83 & 1.35 & 1.23 & 1.52 & -2.64 & 0.00 \\
\hline $\mathrm{Fi}$ & 0.15 & 0.36 & 0.73 & 1.22 & -1.94 & 0.05 \\
\hline $\mathrm{Hh}$ & 0.37 & 0.63 & 0.66 & 1.00 & -2.22 & 0.02 \\
\hline PSV & 0.92 & 1.50 & 1.93 & 1.85 & -1.99 & 0.04 \\
\hline DV & 0.20 & 0.48 & 0.62 & 0.93 & -2.53 & 0.01 \\
\hline FABCOM & 0.48 & 0.80 & 0.95 & 1.31 & -1.98 & 0.04 \\
\hline ALOG & 0.21 & 0.48 & 0.61 & 1.00 & -2.47 & 0.01 \\
\hline
\end{tabular}

No. de niños de familias completas $=163$

No. de niños de familias uniparentales $=60$

para ello, como señalaba Rorschach, es la "tendencia a" subrayando su naturaleza adaptativa e integradora de los elementos de la realidad en conjuntos entendibles y en una sola operación que envuelve los cuatro elementos siguientes: Procesos ideacionales generalizadores, capacidad de disciplina de la función lógica, gran acervo de recuerdos visuales y grado de libertad de las asociaciones. Bohm (1968) refería su condición de expresar también "las atenciones afectivas que estimulan el trabajo intelectual" (p. 90) disponiendo al sujeto a un mejor manejo y control de la realidad. En este sentido puede considerarse como un componente intelectual destinado a la adaptación racional al medio. Según Klopfer (1970, p. 304), Beck las consideraba como representantes del principio de organización y la función de adecuación. La disposición para el rendimiento que subraya Bohm no supone necesariamente "buen" rendimiento, y Rorschach ya advertía sobre la diferencia entre buscar lo "más posible" de lo "mejor posible", pues no todos los que ofrecen res- 
puestas $\mathrm{W}$ tienen condiciones para lograr sus objetivos y si carecen de esta efectividad tenemos también W que indican ambición inadecuada o con poco sustento. Es por ello que Phillips (1956, p. 12) acuerda al porcentaje alto de respuestas $\mathrm{W}$ tanto un nivel más práctico en las relaciones con el medio ambiente y amplitud para el contacto social como un indicio de comportamiento inmaduro e inadecuación social, dependiendo el resultado de la calidad de las interpretaciones de conjunto. En general W es uno de los elementos del rendimiento inteligente.

Tanto $\mathrm{W}$ como $\mathrm{Z} f$ reflejan disposición para la actividad inteligente $\mathrm{y}$ productiva y la presencia de ambos abona a favor de la alternativa inteligente más que si se cuenta con sólo uno de estos componentes del intelecto para la integración racional al medio.

FQf+ FQx+ son símbolos de la calidad formal (FQ) de las respuestas o de la adecuación de las respuestas o de la adecuación de la respuesta a los contornos y formas de la mancha. Se relacionan con el razonamiento formal y su tendencia a, percibir y cumplir las exigencias de la realidad en la vida diaria. El FQf indica la medida del análisis sereno y objetivo donde el razonamiento formal se cumple sin dejarse interrumpir o influir por la intrusión de afectos, ansiedades y preocupaciones. El FQx indica la capacidad para manejar más o menos eficazmente los afectos y las emociones y no permitir que alteren la percepción adecuada (Rovira, 1983, p. 70). Ambos símbolos son buenos indicadores del control de la realidad y representan señales de un buen funcionamiento mental. La calidad formal o FQ tiene cuatro grados de adecuación a los estímulos según corresponda la respuesta a la mancha, la mejor de ellas es la que se designa con el signo positivo (+) donde la respuesta ofrece una forma precisa, extraordinariamente bien desarrollada y articulada y donde hay enriquecimiento de la percepción, y la menos deseable es la que da una percepción arbitraria o distorsionada. FQf+ y FQx+ informan de esa buena percepción y de la madurez cognitiva del sujeto, y la correlación entre ambos símbolos es significativamente alta (Exner, 1974).

CF es símbolo de las respuestas de color forma dentro de las respuestas de color cromático como indicadores de la adaptación afectiva según la secuencia: 
FC: control de los afectos

CF: afectividad más espontánea

C: descontrol, labilidad

Cn: relacionada con alteración orgánica.

Las respuestas CF donde domina el color sobre la forma expresan un descuido o relajación del control cognitivo por lo que la actividad mental del sujeto está invadida, al menos temporalmente, por la emoción (Rovira, 1983, p. 40). Rorschach y Exner designan a CF la condición de una espontaneidad menos controlada o de una afectividad impulsiva. Otros autores lo toman como la medida de la extensión del egocentrismmo, narcicismo o inestabilidad emocional. Klopfer se refiere a la necesidad de contacto caluroso, simpático y que busca un objeto en que fijarse. Bohm agrega la condición de sugestionabilidad e impresionabilidad.

Desde el punto de vista del desarrollo las respuestas $\mathrm{C}$ o color puro predominan en niños pequeños y desde los tres años aparecen las CF y predominan hasta los 16 años sobre las Fe. Estas últimas aumentan paso a paso desde la escolaridad y deben predominar en adultos.

T (FT, TF Y T), símbolo de las respuestas de textura (uno de los tipos de respuesta de claroscuro) o percepción del sombreado en el que predomina la captación sensorial de la superficie de la mancha. Según se privilegie en la respuesta la forma o el sombreado pasan a ser respuestas FT, TF o T. En esta última se carece de forma. Exner interpreta como indicador de necesidades de contacto interpersonal afectivo o ansia de afecto (no la afectividad misma que expresa el color). La vivencia de la necesidad de afecto puede descontrolar la función de realidad (TF y T), como sucede con el niño que pierde a uno de sus progenitores (Exner, 1974, p. 339). FT designa que esta necesidad de contacto compensador es atenuada por la experiencia o por la capacidad de control. Se representa también a T como la "necesidad de agradar" y la búsqueda consiguiente de contacto afectuoso y sensorial. El exceso de $\mathrm{T}$ se da en quienes sufren e "impacto" de la separación con el ser querido, y la falta de $\mathrm{T}$ en quienes han empobrecido sus afectos por deprivación afectiva temprana, como si la resignación ante la carencia frenara la experiencia de emociones. 
Bt, Fi y Hb (botánica, fuego y objetos de hogar) son símbolos de los contenidos de las respuestas que se hallan entre las 23 categorías de contenidos comprendidos por el sistema comprensivo de Exner. Como se comprende, estos contenidos dan indicios de los intereses y las actividades del sujeto respecto de los cuales se orienta con particular preferencia (Beizman, 1968, p. 238), tratando de registrarse el "significado simbólico o proyectivo de las respuestas" (Klopffer y Ainsword, 1970, p. 81).

Las respuestas de plantas, en general, expresan sensibilidad e interés por el arte o la naturaleza (Beinzman), así como actitudes de pasividad o inmadurez (Weigle, 1953, p. 65); Exner menciona también pasividad o inmadurez (1976, Tomo II, p. 102). Este contenido botánico es muy frecuente en niños y más escaso en adultos.

El contenido fuego es considerado como "perturbador" (Klopfer, Weigle) en tanto puede indicar presencia de patología. Indica en general tendencia a reacciones afectivas descontroladas. Durán le añade significado de debilidad, falta de fuerza vital, voluntad manejable ${ }^{2}$. Objetos del hogar son también frecuentes entre las respuestas de niños; Exner las diferencia de Objetos en general que refieren los otros autores y sólo indicarían interés o preocupación por el ambiente físico del hogar.

En la segunda edición del volumen 1 del libro de Exner se menciona un índice de aislamiento constituído por la suma de ciertos contenidos como el de botánica, como indicador de tendencia al aislamiento social por efecto de escaso contacto social con su familia en edad temprana (1974, p. 405).

Las cuatro últimas variables son "valoraciones especiales" del mismo orden que Bohm designaba como fenómenos especiales. El sistema comprensivo implica doce valoraciones especiales de las cuales diez fueron propuestas por Rapaport. Nosotros hemos trabajado con siete de ellas que Exner exponía hasta 1978, resultando significativas las que aparecen en el último lugar de la tabla 3. Estas comparten el significado

\footnotetext{
${ }^{2}$ Halpem (1953) considera que es indicador de represión de impulsos agresivos.
} 
general de las siete (de que su presencia "supone un quebrantamiento del razonamiento, el cual se vuelve arbitrario", con la advertencia siempre de que estas valoraciones son tolerables en niños hasta 7 años de edad con la excepción de la valoración CONTAM (contaminadas).

DV, verbalizaciones desviadas, que impiden la comunicación clara incurriendo en redundancias y hasta en neologismos (Exner, tomo 11). Implica dificultades en el proceso de asociación verbal y en el ritmo de la expresión. El tipo de estas verbalizaciones indica la gravedad, como es el caso de empleo de neologismos.

FABCOM, combinaciones fabuladas, contenidos relacionados sin propiedad o ilógicamente y en una expresión inadmisible. Se evalúan como más patológicas que las DV por estar comprometida la función de síntesis perceptiva y diferenciación lógica ("Una mujer atacando un avión de carga", por ejemplo).

ALOG, lógica inapropiada, en el sentido de contenidos que son justificados con razonamiento excesivo, con arbitrariedad lógica y pensamiento circunstancial y vago. Resulta una comunicación confusa, expresa dificultad en la flexibilidad del pensamiento y transtornos en su curso.

PSV, perseveración, repetición de respuestas, de su contenido o de la parte de la mancha. Se da mayormente en niños y cuando aparece en adultos de modo destacado expresa rigidez cognitiva, dificultad para la sustitución perceptiva o toma de preocupación particular (Exner, tomo III).

En el conjunto que estamos valorando, estas interpretaciones se adjudican más a uno u otro grupo de niños y sus significados deben comprenderse siempre en referencia al nivel de las edades tempranas que estamos involucrando. Conviene ordenarlas según las tres áreas de personalidad, cognitiva, afectiva y actitud in al que se suele distinguir para describir el comportamiento.

\section{Características del área cognitivas:}

Predominan en niños de familias incompletas:

- esfuerzo intelectual por organizar el campo de los estímulos; capacidad de analizar y sintetizar; 
- energía e iniciativa cognitiva;

- disposición para analizar con objetividad;

- voluntad de logro de altos rendimientos (ambición).

- disposición para el mejor manejo de la realidad y la adaptación racional al medio: función de adecuación;

- relajación del control cognitivo;

- sensibilidad e interés por el arte;

- tendencia general a la arbitrariedad de pensamiento;

- dificultades en el proceso de la asociación verbal;

- pérdida de propiedad y lógica en la expresión.

Predominan en niños de familias completas:

- razonamiento formal;

- exactitud en la percepción y cumplimiento con las exigencias de la realidad en la vida diaria;

- análisis objetivo que resiste a distorsiones;

- control de la realidad y buen funcionamiento mental;

- madurez cognitiva.

\section{Características del área afectivas:}

Predominan en niños de familias incompletas:

- tensión afectiva que estimula el trabajo intelectual;

- afectividad impulsiva, tendiente al descontrol;

- inestabilidad emocional, sugestionabilidad;

- egocentrismo, narcisismo;

- necesidad de contacto caluroso y simpático que busca un objeto en qué fijarse;

- tendencia a reacciones afectivas descontroladas.

Predominan en niños de familias completas:

- manejo eficaz de los afectos;

- necesidad de contacto afectuoso o ansiedad de afecto;

- necesidad de agradar.

\section{Caracteres actitudinales:}

Predominan en niños de familias incompletas:

- indicio de comportamiento inmaduro e inadecuación social; 
- pasividad y dependencia: inmadurez;

- debilidad, falta de carácter o fuerza vital;

- tendencia al aislamiento social.

En el Cuadro 2 aparece el resumen de estas interpretaciones por grupo de niños y por área de personalidad. Según este resumen el mayor número de variables Rorschach diferenciales pertenecen al área cognitiva y aparentemente sería el aspecto psíquico más afectado por la uniparentalidad. Pero en una apreciación más sostenida puede advertirse que lo que realmente tiene primacía es una misma condición que liga estructuralmente las tres áreas del psiquismo y distingue a unos niños

\section{Cuadro 2}

\section{Resumen interpretativo de las variables Rorschach significativas Ordenadas por tipo de familia por área de personalidad}

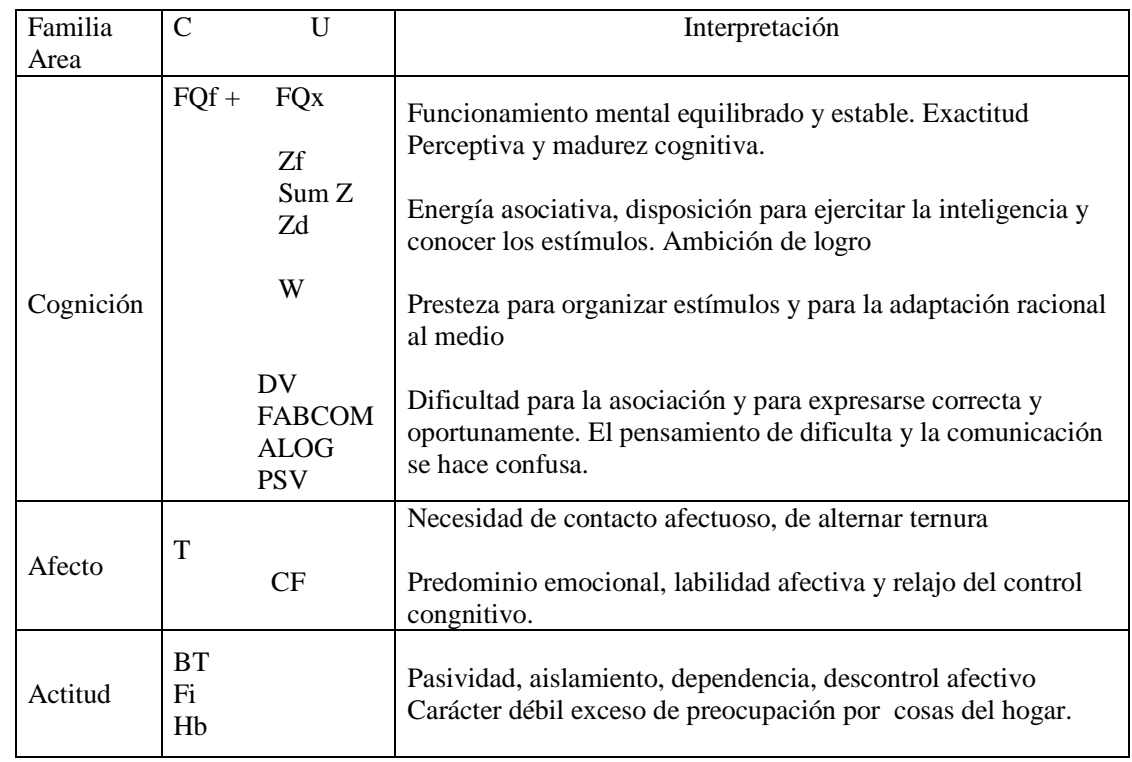

C: Grupo de hijos de familias completas.

U: Grupo de hijos de familias uniparentales. 
de otros. Esta condición se relaciona con la estabilidad psíquica: equilibrio de funciones, control y medida en las respuestas. Estabilidad cognitiva, estabilidad afectiva y estabilidad en el comportamiento en general parecen distinguir a los hijos de familias completas frente a los uniparentales en los cuales los indicios de inestabilidad están en la base de su cognición, afecto y actitud. Estos son diferencialmente algo más inquietos, más alocados en sus juicios y reacciones; muestran más entusiasmo para la actividad mental, más vivacidad emocional y más sensibilidad al contacto interpersonal, pero al mismo tiempo desmedida en el juicio y precipitación en la reflexión, labilidad afectiva con tendencia al descontrol así como dependencia e inseguridad y en el comportamiento decisional. Aquéllos son más equilibrados, éstos más nerviosos; más medidos contra más aventurados.

A la sensatez en el juicio que parece caracterizar a los de familias completas se suma la disposición para mostrar su necesidad de afecto y ternura; esperan este tipo de contacto y no temen mostrar esta necesidad, sin que por ello lleguen al nivel de ansiedad patológica o avidez de afecto. En los uniparentales puede existir la misma necesidad pero temen exhibida o la niegan y no sacan a luz entonces (falta $\mathrm{T}$ ) su necesidad de cariño, como si ésta estuviera reprimida. Sin embargo, tienen más relajada su responsividad emocional en tanto reactividad a los estímulos del ambiente y por ello aparecen más alterables o excitables y con propensión al descontrol. Parecen soltar sus emociones y guardar para sí sus sentimientos.

A modo de referencia es procedente comparar los promedios obtenidos de las variables significativas con los promedios de los baremos de Lima obtenidos por nosotros- y de Exner, según se muestra en la tabla 3. En general los promedios de nuestro trabajo cuando son comparables se mantienen a la altura de los del baremo de Lima y algunos muestran distancia con los que presenta Exner. La referencia de Lima autoriza a ubicar los promedios calculados en este trabajo dentro del rango de la normalidad y, en consecuencia, a interpretar las variables significativas como rasgos normales de personalidad de nuestros niños. En tal sentido, las características diferenciales de personalidad resultantes son variaciones del comportamiento normal y no desviaciones patológicas ni signos de noxas 
psiquiátricas. Deben tomarse en el contexto de la salud y como rasgos de comportamiento más o menos acentuados en los niños, con mayor o menor presencia en unos niños que en otros. En suma, nuestros resultados han devenido en rasgos caracterológicos de la personalidad infantil comparables por su mayor o menor presencia en los probandos de estudio. La secuela psíquica que nos habíamos fijado como objetivo al iniciar nuestro trabajo de comparación es de orden caracterológico y no clínico: unos tienen más de algunos rasgos que de otros.

\section{DISCUSIÓN}

La comparación de protocolos Rorschach de niños de familias uniparentales y de niños de familias completas ha permitido establecer algunos rasgos de comportamiento diferencial que pueden adjudicarse a la condición de crecimiento en situación de uniparentalidad. Expuestos de una manera algo más comprensiva, estos rasgos son ordenados de la siguiente manera:

1. Manifiestan energía, esfuerzo e iniciativa para entregarse al trabajo intelectual con disposición para la adaptación racional al medio y aspiración de alcanzar altos logros. En esto se dan con cierto exceso de entusiasmo que relaja el control cognitivo y puede hacer incurrir al pensamiento en arbitrariedad. La ambición de metas elevadas hace perder precisión al proceso asociativo, generando mengua en el ajuste intelectual a las condiciones del ambiente.

2. Tienden a la inestabilidad emocional por la pérdida del control interior de los afectos. Ello hace que se muestren más ansiosos e impulsivos, propensos a las reacciones afectivas descontroladas. Paralelamente inhiben sus necesidades de contacto afectuoso y sus concomitantes sentimientos y vivencias de ternura y sensibilidad para el contacto interpersonal. Su dificultad para el manejo afectivo hace que sean más egocéntrico s y algo más temperamentales.

3. Entre sus actitudes generales destacan su pasividad y dependencia y consiguiente tendencia al aislamiento con resultados que denuncian debilidad de carácter inmadurez e inadecuación social. 


\section{Tabla 3}

Comparación de los promedios obtenidos de las variables Rorschach significativas con los promedios correspondientes de los baremos de Lima y de Exner

\begin{tabular}{|c|c|c|c|c|c|c|}
\hline \multirow{2}{*}{ Variables } & \multicolumn{2}{|c|}{ Tipo de familia } & \multicolumn{2}{|c|}{ Baremo de Lima } & \multicolumn{2}{|c|}{ Baremo de Exner } \\
\hline & C & U & 9 años & 10 años & 9 años & 10 años \\
\hline $\mathrm{Zf}$ & 7.63 & 9.20 & 7.32 & 8.44 & 10.70 & 10.20 \\
\hline Sum Z & 21.72 & 26.73 & 20.84 & 24.65 & & \\
\hline $\mathrm{Zd}$ & -0.51 & -1.61 & -0.74 & -0.80 & -0.07 & -0.12 \\
\hline W & 5.02 & 6.82 & 5.20 & 5.59 & 9.80 & 9.30 \\
\hline FQf+ & 0.17 & 0.05 & 0.94 & 0.12 & & \\
\hline $\mathrm{FQ}+$ & 0.72 & 0.32 & & & & \\
\hline CF & 0.63 & 1.03 & 0.64 & 0.66 & 2.00 & 2.10 \\
\hline $\mathrm{T}$ & 0.52 & 0.18 & 0.52 & 0.45 & 0.90 & 0.90 \\
\hline $\mathrm{Bt}$ & 0.83 & 1.35 & & & & \\
\hline $\mathrm{Fi}$ & 0.15 & 0.36 & & & & \\
\hline $\mathrm{Hb}$ & 0.37 & 0.63 & & & & \\
\hline PSV & 0.92 & 1.50 & 0.67 & 0.72 & 0.40 & 0.30 \\
\hline DV & 0.20 & 0.48 & 0.23 & 0.22 & 2.10 & 1.00 \\
\hline OFABCOM & 0.48 & 0.80 & 0.28 & 0.63 & 0.80 & 0.80 \\
\hline ALOG & 0.21 & 0.48 & 0.48 & 0.24 & 0.60 & 0.60 \\
\hline
\end{tabular}

Algo les falta y hace que eleven sus metas más allá de lo que pueden alcanzar y, por otro lado, eso mismo que les falta es raíz de su impulsividad y de reacciones desmedidas por efecto del ansia de logro. Esto parece ser vivido en la forma de un sentimiento de pérdida, de carencia o de incompletud asociada a la condición de uniparentalidad. La carencia de un progenitor se traduce en carencia psíquica y búsqueda ansiosa de comportamiento y de resarcimiento que es lo que puede verse en la base de esa inquietud general necesitada de reconocimiento que estimula el trabajo intelectual con pretensiones de abarcarlo todo y conseguir altos rendimientos que rediman o compensen la sensación de haber sido mellados o sustraídos en su esencia. En ese propósito se relaja el control cognitivo y pierden sensatez en tanto arriesgan más intelectualmente y 
aumentan sus probabilidades de yerro y frustración. Esa inquietud básica es propiamente excitación afectiva que igualmente disminuye el control de las emociones dando predominio a la impulsividad y reacciones descompuestas que no tardan en menoscabar la propia imagen con repercusiones de retraimiento, inseguridad y necesidad de dependencia. El sentimiento de pérdida y daño esencial, por otro lado, aviva su susceptibilidad y les hace temerosos de nuevas pérdidas de modo que reaccionan con evitaciones e inhiben en general sus necesidades de contacto interpersonal como si, orgullo y temor de por medio, no las necesitaran y pudieran prescindir de ellas sin consecuencias mayores. Todo este manejo dificultado de su vida interior va edificando paulatinamente las actitudes que hemos visto destacar sobre inadecuación social como la debilidad de carácter y la dependencia.

Si bien estos rasgos de carácter no llegan a desviaciones extremas que linden con lo psicopatológico, el carácter de pérdida que explica el conjunto no puede dejar de asociar un efecto depresivo general que mueve a inquietud y necesidad de resarcimiento. El comportamiento resultante de la uniparentalidad tiene una constante depresiva que signa a toda la personalidad y se manifiesta en merma de la sensatez cognitiva y de la estabilidad emocional, en la medida de particularidades de carácter. Como se sabe el componente depresivo en primera instancia excita, moviliza, inquieta $\mathrm{y}$, por tanto, dispone a la personalidad a arriesgar más de lo establecido y que la sensatez indica, quizá en la medida de la necesidad de resarcimiento o en la compensación de lo perdido. Y es así que toma sentido la tensión, la excitación, la ambición y el riesgo como motivadores particulares de quienes crecen dentro de familias incompletas. Este arriesgar cognitivo, afectivo y actitudinal puede ser el comienzo de tipos y estereotipos conductuales y puede acentuarse y deriva en trastornos y problemas sociales y esto debe entenderse como alcances ajenos a los efectos de la mera uniparentalidad que no sobrepasan los límites de la caracterología.

Al parecer, una de esas exageraciones fue la de hacer pensar que la carencia de padre conduce necesariamente a la propensión psicopática o disocial, como lo hemos recordado antes (Munsiger, 1978, p. 266). Autores más recientes se cuidan de llegar a esas conclusiones. El propio 
McConnell, que resume los trabajos de los Harlow, no deja de recalcar que sólo "algunos" de los niños con privación temprana de padre desarrollaban conductas extremadamente masculinas que podrían dar lugar a comportamiento antisocial. Y menciona también a E. M. Hetherington y a su estudio sobre hijas de padres divorciados y de madres viudas de cuyo grupo "sólo unas cuantas tenían problemas notables de conducta" (ob. cit., p. 464), subrayando el hecho de que tanto el trastorno en sí como la antisocialidad no son norma de esa condición de crecimiento. Nuestros resultados en este trabajo coinciden con los que obtuvimos en 1994 sobre el tipo de problemas que derivan de la uniparentalidad masculina, pues el grueso de esos niños más que problemas de conducta antisocial mostraba problemas de orden afectivo.

En referencia a lo que se observa en la mayoría de los niños de este trabajo, para no seguir haciendo hincapié en las excepciones, los caracteres de personalidad que hemos diferenciado no son ajenos a lo que resulta en estudios de los otros autores si se les recuerda aisladamente. McConnell hace referencia a la pasividad y dependencia; otros varios como Porot, Spitz Levy, Lowrey, Bowlby, Bender, Heuyer aluden a la inhibición de afectos que subrayan como incapacidad o inaptítud para el intercambio de afectos; el grupo citado por la revista Psykhe (Muller y Cooper, Goodyear, Yema y Finlay) encuentra también ansiedad y retraimiento; las autoras clásicas Burlingham y Freud: insatisfacción de sentimientos, Horney: carencia afectiva esencial. Sólo habría de agregar el ansia de resarcimiento cognitivo y así cuadre en conjunto el comportamiento descrito para los hijos de la uniparentalidad, siempre en términos de rasgos caracterológicos. Cabe ahora hacer la pregunta de si estas inclinaciones del carácter son favorables o desfavorables, positivas o negativas. Esta excitabilidad de. fondo que genera la experiencia de pérdida, relaja el control cognitivo y suelta los impulsos ¿es un obstáculo o un facilitador del desarrollo personal? Al comenzar nuestro trabajo, en el punto 3 , formulamos como objetivo determinar si había una secuela psíquica en niños que crecían dentro de familias incompletas y queriéndolo o no esperábamos un resultado defectivo; pero en el curso de nuestro hallazgo hemos ido percatándonos -la dialéctica está en todas las cosas- de que no todo es adverso y que los niños estudiados pasan por una situación de cambio y de 
nuevas expectativas. En efecto, tenemos una doble perspectiva discutida en las fuentes de nuestra profesión que merece tenerse en cuenta en el punto ahora tratado. Es equivalente al doble punto de vista con que se enfoca la adaptación y su contrapartida; la inadaptación y las conveniencias de una y de otra. El equilibrio y la sensatez -supuestas características- de los niños que crecen en familias completas y que aparentemente usufructúan de la mejor opción, son a la vez indicadores de quietud o inercia y pueden llevar al anquilosamiento y la improductividad pues estabiliza y adecúa al individuo a su ambiente pudiendo quedar éste mezclado y sin identidad propia. En el otro lado, la inquietud y el riesgo libran al individuo de perderse en el montón, pero lo sumen en una inestabilidad permanente. En un estudio de predictores de longevidad, Friedman el al (1995, p. 69) siguieron el rastro a los niños evaluados por Terman en la década del 40 y de cuya muestra de entonces sólo sobrevivía la mitad. Se encontró que una causa "psicosocial" de la muerte prematura de la otra mitad fue el divorcio paren tal durante la infancia. Este resultado argumenta a favor de consecuencias defectivas de la uniparentalidad; pero a ello puede oponerse una perspectiva optimista que lleva a apreciar esa excitabilidad generada por la experiencia de pérdida en la medida de un estresor movilizante de la acción y la creatividad en el mismo sentido en que Lazarus reclama estudiar los afectos positivos del estrés y su valor de promoción de vida y de la conocida frase de Bernard Shaw: "el progreso se debe al hombre insensato". Quienes se han ocupado de la angustia y la ansiedad no sólo refieren sus efectos preocupantes, son muchas las biografías de hombres célebres que derivan el genio del infortunio. Quizá podría parecer conclusiva una solución ecléctica que combine el equilibrio con la inquietud, pero como se trata de explicar la consecuencia de la uniparentalidad en los hijos y desde que éstos hacen un comportamiento normal algo diferente del comportamiento también normal de los que crecen en familias completas cabe considerar la uniparentalidad como una de las alternativas familiares posibles, y no como subyace en nuestros planteamientos iniciales (un fenómeno social de cola perniciosa). En este esclarecimiento cabe también abrir la posibilidad de que se esté montando un mito sobre este tipo de familias y se las utilice como pretexto para descargar tensiones provenientes de otras fuentes de la misma manera de cómo se usan otros 
motivos para zaherirse unos grupos con otros o unas clases con otras y no se ventila la raíz concreta de las discordias.

Hay, sin embargo, un aspecto que de todos modos debe subrayarse y es la impresión general de que el conjunto de signos de comportamiento que se han ido alineando entre los hijos de familias incompletas tienen como base la inseguridad o un incremento de la inseguridad normal que compromete en general a todas nuestras familias. Sea por la experiencia real de pérdida o por el mito que se teje sobre la uniparentalidad, los niños de esta condición se muestran algo más inseguros (léase más ansiosos, poco menos sensatos, algo más inestables, etc.). Independientemente de que sea o no productiva esta inseguridad, nos quedamos con el hecho de que se da en mayor medida y dentro de lo normal para nuestras familias en la condición de vida familiar incompleta. La razón de tener una fuente menos de apoyo -falta de uno de los padres- se asocia rápidamente al incremento de inseguridad que estamos viendo, pero ello no conduce a ubicar su causa real y profunda. La ausencia de uno de los padres no tiene porqué significar necesariamente motivo de inseguridad por la sencilla razón de que la seguridad familiar no procede de alguno o de los dos padres sino de las condiciones sociales de apoyo y resguardo a la familia. El incremento de inseguridad o el efecto depresivo resultante del sentimiento de pérdida, entonces, se produce en un marco de inseguridad total o de inquietud depresiva general donde cada familia es tan deleznable que cualquier ruptura o ausencia (como la de uno de los padres) acrecienta la inseguridad. $\mathrm{Y}$ al decir esto estamos ligando nuestro objeto de estudio con la realidad concreta que lo rodea (poco tonificante y muy amedrentadora). Como en un castillo de naipes, una estructura familiar débil puede desplomarse con el retiro de alguno de sus frágiles soportes. Y así como no podríamos culpar del desastre al soporte rendido cometeríamos un error si adjudicamos a la uniparentalidad la causa de inestabilidad o inseguridad de los hijos. Bien puede ser, más bien, un signo de la inseguridad social que rodea a nuestras familias, tanto como lo es el soporte de la debilidad de toda la estructura familiar.

Como estamos viendo es posible enfatizar de distinto modo el fenómeno estudiado. Primero hemos subrayado el sentimiento de pérdida que se enlaza a la falta de uno de los padres, luego el significado depresivo 
que subyace y exige resarcimiento y, por último, el contenido de inseguridad recogido entre los rasgos diferenciales encontrados. Ya habíamos anotado que cuando estos modos se acentúan o exageran pasan a constituir las noxas psiquiátricas o "formas de oposición" de los niños a las condiciones de disgregación e inseguridad ambiental. Pero antes de llegar a estas exageraciones, los comportamientos infantiles comienzan por ser particularidades -estilos o rasgos acentuados de carácter, lejos aún de conformar síndromes-, que no pueden ser sino intentos personales y precoces de resolver las dificultades derivadas o expresadas por la uniparentalidad. No otro sentido puede tener la expresión de "energía e iniciativa para entregarse al trabajo intelectual" junto con las de "alcanzar altos logros", "entusiasmo que relaja el control cognitivo", "propensión a las reacciones descontroladas", "pretensiones de abarcarlo todo", etc. Los niños parecen arriesgar para el cambio como no lo hacen los que se crían en hogares completos. Claro, se trata de empeños infantiles y de formas de participación de las individualidades en la problemática del grupo regularmente no acompañadas por el éxito, pero que deben' ser comprendidas en su dimensión de aporte temprano a la lucha de las familias por su salud y seguridad. Son rasgos de carácter con orientación productiva antes que "formas de oposición" y desde su surgimiento en la niñez implican disposición al sacrificio mostrado en los otros rasgos complementarios descritos (como "inhibición de sus necesidades de afecto", "egocentrismo", "pasividad y dependencia", "tendencia al aislamiento" y otros). Es deducible que quizá por no tener debidamente en cuenta el significado de aporte de las particularidades infantiles, éstas vayan derivando en exageraciones, oposiciones y síndromes que todos quisiéramos evitar. No estamos elaborando con esto una interpretación meramente romántica. Lejos de ello, la configuración de los datos hallados plantea la necesidad de revalorar los comportamientos individuales dentro de la familia y su problemática, en este sentido, las reacciones infantiles no son menos dignas de consideración que las de los adultos. En las situaciones de crisis por las que atraviesan las familias se movilizan todos sus integrantes sin importar edad o aporte de cada uno, es más importante cuando en el esclarecimiento familiar no es posible contar con la presencia de todos sus miembros. 
Por último, debemos reconocer la utilidad del test de Rorschach por habemos permitido diferenciar los aspectos de personalidad que se sensibilizan en los niños por la ausencia de uno de los padres. Reconocemos, igualmente, que la prueba cuenta con muchos otros renglones de información que pueden contribuir aún más al enriquecimiento de estudios como el que por ahora damos término.

\section{RESUMEN Y CONCLUSIONES}

El número de familias en las que falta uno de los padres es cada vez más numeroso en sociedades que como la nuestra siguen el régimen monogámico. Los hijos que crecen con la conducción de sólo uno de los padres presentan diferencias en relación con los que tienen ambos padres. A nosotros nos interesan las diferencias psicológicas o de personalidad. En un trabajo anterior que titulamos "El transtorno mental por ausencia paterna" comparamos a un grupo de niños de familias completas con otro de familias uniparentales y encontramos que el área emocional era la más afectada en ausencia del padre. Esta vez queremos llegar a describir cuáles son los aspectos de la personalidad infantil más sensibles a la pérdida de uno de los padres y trabajamos bajo la hipótesis general de que debe existir una secuela psíquica especificable.

Uno de los métodos más adecuados para estudiar la personalidad infantil es el Psicodiagnóstico de Rorschach, respecto del cual hemos elaborado antes su baremo para niños de nuestra capital de acuerdo al sistema comprensivo de Exner que garantiza mayor validez y fiabilidad a la prueba. Esto hace que contemos con las condiciones necesarias para cumplir con el propósito de escudriñar la personalidad de los niños de nuestro medio, emprendiendo un estudio exploratorio de comparación entre grupos por mediación de una prueba psicológica.

En aplicación individual, hemos administrado el Rorschach a 60 niños de familias uniparentales ya 163 de familias completas, entre 8 y 11 años de edad en distribución equitativa por sexo y se ha recurrido a la $t$ de Student y al paquete SPSS V. 4.0 para contrastar en uno y otro grupo las 68 variables del test. 15 de estas variables han alcanzado la significación 
requerida de .05 que son las siguientes:

$\begin{array}{ll}\text { Zf } & \text { Bt } \\ \text { SurnZ } & \text { Fi } \\ \text { Zd } & \text { Hh } \\ \text { W } & \text { PSV } \\ \text { FQf+ } & \text { DV } \\ \text { FQx+ } & \text { FABCOM } \\ \text { CF } & \text { ALOG } \\ \text { T } & \end{array}$

En términos de personalidad la traducción de estas variables es como sigue. En el área cognitiva hay mayor estabilidad entre los hijos de familias completas dado que ajustan mejor su percepción a los estímulos del ambiente y enjuician con mayor ponderación. Los de familias uniparentales son más inquietos y motivados en esta área pero más propensos a desmedirse y errar en el juicio. En el área afectiva, los uniparentales son algo más impulsivos y egocéntricos y tienden a reprimir $\mathrm{u}$ ocultar sus necesidades de afecto. Y en el área de las actitudes los uniparentales se muestran más necesitados de aprobación así como, en general, más pasivos e inconstantes que sus homólogos de familias completas que expresan mayor autonomía y estabilidad en el carácter.

Las conclusiones que se desprenden de nuestro trabajo son las siguientes:

a) El test de Psicodiagnóstico de Rorschach ha sido adecuado para registrar los rasgos de personalidad infantil más sensibles a la condición de uniparentalidad.

b) Los promedios obtenidos de las variables Rorschach se hallan comprendidos dentro del rango de normalidad y, por tanto, las interpretaciones que derivan expresan rasgos normales de personalidad (no patológicos).

c) La característica más general que diferencia la personalidad de los niños de familias incompletas de los de familias completas reside en la estabilidad psíquica (equilibrio de funciones, control y medida en las reacciones) más favorable a los segundos. 
d) En el área cognitiva los niños de familias uniparentales tienden a percibir más unilateralmente los estímulos frente a la precisión y ponderación en el juicio de los de familias intactas.

e) En el área afectiva, los uniparentales son más hábiles y son propensos a reprimir sus necesidades de afecto. Los de familias completas controlan mejor sus impulsos y no temen a expresar sus necesidades emocionales.

f) En cuanto a actitudes, los uniparentales son más pasivos, dependientes e inconstantes, en tanto que sus homólogos de familias completas se muestran más estables y con mayor autonomía.

\section{REFERENCIAS BIBLIOGRÁFICAS}

Ames, L.B. (1961). El Rorschach infantil. Buenos Aires: Paidós.

Beck, S. (1966): El examen de la inteligencia y de la personalidad del niño. Buenos Aires: Paidós.

Beck, S. J. (1967). Le test de Rorschach. Presses Universitaires de France: Paris.

Beizmann, C. (1968). El Rorschach en el niño de tres a diez años. (Estudio clínico y genético de la percepción infantil). Madrid: Aguilar.

Burlingham y Freud, A. (1964). Niños sin familia. Barcelona: Luis Miracle.

Bohm, E. (1968): Manual del psicodiagnóstico de Rorschach. Barcelona: Científico-Médico.

Campo, V. (1987). Los niños y el Rorschach: Aspectos clínicos, investigación y aplicación. Valencia: Promolibro.

Crespo López Castilla, M. (1985). El Psicodiagnóstico de Rorschach en un grupo de niños institucionalizados y no institucionalizados. Tesis no publicada. P.U.C., Lima.

Exner, J. E. Jr. (1974). Sistema Comprensivo del Rorschach. Tomo I. Madrid: Pablo del Río.

Exner, J. E. Jr. (1976). Sistema Comprensivo del Rorschach. Tomo II. Madrid: Pablo del Río.

Exner, J. E. Jr. (1986). The Rorschach: A comprehensive system. Volume 1: Basis foundations. New York: A Wiley Interscience Publication.

Exner, J. y Wiener, E. (1982). The Rorschach: A comprehensive system assesment of children and adolescente. Volume I. New York: Bayville, Wiley.

Duran, L. Ma. (1981). Introducción a la práctica del Rorschach. Barcelona: Herder, 
Friedman, S., Tucker, H. y Schuwartz (1995). Psychosocial and behavioral predictors of longevity. The ageng and death of the "termiter". American Psychologist. 50 (2),69.

Fairlie, A. et al. (1995). El transtorno mental por ausencia paterna. Lima: UNMSM.

Frisancho, D. (1988). Contribución a la elaboración de un perfil Rorschach Andino. Tesis doctoral no publicada, UNMSM, Lima.

Halpern, F. (1953). A clinical approach to children's Rorschach. New York: Grune y Stratton.

Heuyer, G. (1962). Introducción a la psiquiatría infantil. Barcelona: Luis Miracle.

Klopfer, B. \& Ainsword, M. (1970). Development in the Rorschach thechnique. New York: Harcourt, Brace and World.

Pearson, A. (1958). Transtornos emocionales de los niños. Buenos Aires: Paidos.

Phillips, Y. \& Smith, J. G. (1953). Rorschach interpretation. Advanced technique. New York: Grune y Stratton.

Mc Connell, J. V. (1978). Psicología. Interamericana. Méjico.

Michaux, L. (1962). El niño perverso. Barcelona: Luis Miracle.

Munsinger, H. (1978). Desarrollo del niño. México: Interamericana.

Porot, M. (1962). La familia y el niño. Barcelona: Luis Miracle.

Psykhe (1992). No. 1, Santiago de Chile.

Rausch de Traubenberg, N. (1977). La práctica del Rorschach. Madrid: Pablo de Río.

Rapaport, D. (1965). Test de diagnóstico psicológico. Buenos Aires: Paidos.

Rorschach, H. (1967). Obras menores o inéditas. Madrid: Morata.

Rovira, F. Ma. (1983). El Rorschach: Nuevas aportaciones de J. E.Exner al sistema comprensivo. Madrid: Siglo veintiuno.

Saggino, A (1988). El Rorschach en el sistema comprensivo de John E., Exner. Barcelona: Bulzoni.

Schafer, R. (1954). Psychoanalytic interpretation in Rorschach testing. New York: Grune \& Stratton.

Spigelman G., Spigelman, A, Englesson I. (1991). Hostility, aggression, and anxiety levels of divorce and nondivorce children as manifested in their responses to projective test. : J. Pers. -Assessment. 56(3),438-452.

Spigelman G., Spigelman, A (1991). Depression and distress in divorce and nondivorce children reflected by the Rorschach test. Journal Personality Assessment. 57(1), 120-129.

Weigle, C. (1988). Cómo interpretar el Rorschach. (Su articulación con el psicoanálisis). Buenos Aires: Artigas Suárez.

Zuk G. H. (1984). Psicoterapia familiar. Un enfoque triádico. Méjico: Fondo de Cultura Económico. 